\title{
AS POLÍTICAS SOCIAIS BRASILEIRAS - o que há de novo?
}

\author{
INTRODUÇÃO
}

\author{
Isabel P.H. Georges * \\ Cibele S. Rizek** \\ Marco Ceballos***
}

$\mathrm{O}$ ponto de partida que inspirou tanto a reflexão como a elaboração dos textos desse dossiê, em suas incursões conceituais e empíricas, foi um quadro de construção múltipla da definição de assistência como questão que se desdobra em lugar do social, lugar de construção de relações sociais e, ao mesmo tempo, ação do Estado, isto é, espaço de reconhecimento, espaço de instrumentalização, de trocas, de interface entre o Estado social (entenda-se, assistencial) e os sujeitos que se conformam como públicos-alvo.

De certa forma, esse ponto de partida se encontra no artigo de abertura de Bruno Lau-

\footnotetext{
* Doutora em Sociologia. Pesquisadora do Institut de Recherche pour le Développement, França (IRD). Professora credenciada do PPGS e pesquisadora associada no departamento de Sociologia da Universidade Federal de São Carlos (UFSCar-DS).

45 bis avenue de la Belle Gabrielle, 94736 Nogent-s-Marne, França. isabel.georges@ird.fr

** Doutora em Sociologia. Professora do Programa de Pós Graduação em Arquitetura e Urbanismo do IAU/ Universidade de São Paulo. Pesquisadora do Centro de Estudos dos Direitos da Cidadania, também da Universidade de São Paulo.

Av. Trabalhador São-Carlense, 400. Centro. Cep: 13566590. São Carlos - São Paulo - Brasil. cibelesr@uol.com.br

*** Doutor em Sociologia. Professor da Escola de Sociología, Faculdade de Humanidades e Ciências Sociais da Universidade Andrés Bello, UNAB, Viña del Mar, Valparaíso. Quillota 980, $5^{\circ}$ piso. Viña del Mar - Valparaíso - Chile. marco.ceballos@unab.cl
} 
cular das mulheres - nesse empreendimento em escala global de transformação do regime de governo, o que levou à ampliação dos espaços de disciplinarização que se estendem desde o âmago das relações familiares e de gênero ( $c f$. Y. Garcia dos Santos, nesse dossiê) até a criação de um espaço contínuo de relações de assistência, passando pelo controle e chegando à repressão (cf. G. De Santis Feltran, nesse dossiê) e à construção do que corresponderia a uma "cidadania assistencial" das mulheres, no caso chileno ( $c f$. M. Ceballos, nesse dossiê). A partir dessas indicações, propusemo-nos, de um lado, a desvendar alguns dos mecanismos de governo nas constelações das políticas de assistência ( $c f$. artigo de Rizek, Carvalho e Camargo nesse dossiê) através dos diversos serviços e programas e suas formas de concretização; de outro lado, ansiávamos por flagrar os percursos e perambulações dos seus "beneficiários" potenciais. Esses sujeitos, "usuários", "cidadãs", "eleitores”, “consumidores”, "moradores", nos seus esforços de se autoempreender, "públicos-alvo" das múltiplas iniciativas de capacitação, tateiam os túneis sinuosos dos labirintos da assistência, buscam descobrir as contrapartidas dos seus "engajamentos", para obter acesso a seus direitos. Tais direitos, longe de estar garantidos ou facilmente disponíveis, encontram-se do lado fraco do balanço da meritocracia erigida sobre a base das concepções do "capital humano", legitimação universal da permanência dos pobres "no seu lugar" e da punição às reivindicações avaliadas como "injustas" (Wacquant, 2004).

Além desse ponto de partida, buscamos refletir e contemplar os pontos de inflexão na \& trajetória das políticas de assistência e nas forลे mas pelas quais foram enunciadas e compreendidas, já que, até o final dos anos oitenta (especialmente depois da crise que caracterizou essa década), tais políticas foram vistas como elementos residuais, políticas compensatórias, definidas a partir das relações com o universo do acesso ao trabalho assalariado, em especial como elemento a ser considerado a partir das dualidades que se desenhavam, até então, no âmbito do mercado de trabalho: emprego e desemprego, trabalho formal e trabalho informal. Ao longo dos anos noventa, as políticas sociais se autonomizaram face ao mundo do trabalho, que já não oferecia a dimensão e a perspectiva de proteção e integração em um contexto de desemprego em massa e de crise econômica aguda em âmbito mundial. A partir de 1997 e 1998, anos marcados pela crise asiática, desenhou-se um novo ponto de inflexão que apontava para as políticas sociais como demonstração e legitimação dos efeitos da implantação da economia neoliberal.

Entre o final dos anos noventa e o início dos anos 2000, algumas diferenças se anunciavam: referiam-se, sobretudo, às expectativas sobre a recuperação da tessitura e da trama social, de um lado como horizonte e, de outro, como demanda, como reabilitação de um léxico específico da proteção social. Os elementos que compuseram esse quadro de reabilitação ajudariam, então, a explicar a chegada ao poder, no âmbito latino-americano, de governos reconhecidos como "de esquerda": os governos Lula no Brasil, Lagos no Chile, Kirchner na Argentina e Vasquez no Uruguai. Diante do crescimento do número de países governados por partidos desse espectro político, o FMI, o Banco Mundial e o Banco Interamericano redescobririam sua missão, produzindo um contexto em que falar do "social" ganhava legitimidade, ilustrado nesse dossiê pela análise da gênese do programa Bolsa Família no Brasil (cf. Georges e Ceballos). Nasciam, assim, os objetivos do milênio, que colocavam em pauta o engajamento dos países na redução da pobreza pela metade entre 2002 e 2004, ao mesmo tempo em que o contexto e o cenário econômico permaneciam inalterados.

Em meio a essas inflexões, a América Latina começava a se configurar como um "laboratório” de políticas sociais. Esse mesmo caráter acabou por colocar um conjunto de questões sobre as razões dessa conformação, em que se combinavam um quadro econômico 
pouco ou nada alterado em relação às crises anteriores e a constituição de novas demandas que redesenhavam o contexto de redescoberta e redefinição do "social". A partir dos anos noventa, os processos de abertura democrática, combinados ao crescimento econômico e à redução da dívida externa, sob a égide dos organismos internacionais (FMI e Banco Mundial), compuseram um cenário no qual alguns países intensificaram a liberalização econômica até seu limite máximo, colocando em risco sua legitimidade, o que conduziria ao encorajamento, inclusive de seus principais protagonistas e atores, à adoção de medidas de redução da pobreza, ainda que de baixo custo. Teria havido, então, uma busca pela concretização - e (ou) "invenção" - de "novos" programas sociais, capazes de responder a esse novo contexto, acompanhados da busca de novas técnicas e novos modos de intervenção, novas formas de aferição e avaliação (benchmarking) social. A concretização dessas políticas públicas - como resultado do consenso e do acordo de um conjunto de interesses políticos e econômicos - acabaria finalmente por torná-las rentáveis, especialmente em alguns setores (Georges e Ceballos, op. cit.). Nessa conjuntura, o caso brasileiro se caracterizava, então, por processos complexos que teriam produzido marcadores e indicadores que apontariam para a aquisição de direitos - tal como foram formulados pela Constituição brasileira de 1988 - concomitantes às conquistas do processo de abertura democrática, reivindicada por ampla e legítima mobilização. Entretanto, a conquista de direitos políticos, no âmbito dessas transformações, não produziu, como seu corolário e desdobramento, o mesmo resultado do ponto de vista dos direitos sociais. Ao longo dessas transformações, um conjunto nada desprezível de processos e injunções levou a economia brasileira a se configurar como a sexta economia capitalista do mundo, combinando (Singer, 2013) crescimento econômico e suas oscilações e reprodução de desigualdades que parecem - ao que indicam alguns autores - di- minuir relativamente menos do que a pobreza e a miséria. Nas últimas décadas - em especial a partir dos anos 2000 -, observou-se um duplo movimento de criação de empregos formais, embora caracterizados por baixos salários, assim como de postos de trabalho precarizados, além de uma relativa estabilidade do mercado de trabalho, apesar da desaceleração dos anos recentes (2011/2014) (Leite, 2011). O momento presente apontaria, assim, duplicidades, disjunções, processos de conformação complexa que parecem se relacionar a uma transformação da composição do emprego a partir das redefinições da inserção brasileira nos processos mundializados de financeirização desde os anos noventa. Esse novo panorama apontaria ainda para um deslocamento de parcelas do emprego - crescentemente inseridas no setor de serviços (com salários em torno dos 1000 reais) - e para a reabsorção de amplas parcelas desempregadas (em especial aquelas expulsas do mercado entre 1994 e 2002) (Braga, 2012; Cenedic, 2013). Ao mesmo tempo, alguns autores apontam um recrudescimento das condições de trabalho, o que se faz notar pelo número de acidentes e mortes no trabalho, pela rotatividade da força de trabalho e pelo aumento das terceirizações. Em conjunto com a ampliação da base do assalariamento, o período também foi marcado pela instituição das políticas sociais redistributivas, como o Bolsa Família, bem como pelo significativo aumento do salário mínimo desde o início do primeiro Governo Lula.

Combinando o caráter de praça de valorização financeira e a produção e exportação de commodities, é possível reconhecer, no âmbito do Brasil dos anos 2000, a importância econômica do agronegócio, ${ }^{1}$ ao lado das políticas de incentivo à agricultura familiar. A aparência dualizada parece se repetir em relação

${ }^{1}$ Leda Paulani, Brasil Delivery, São Paulo, Boitempo, 2008. A inserção da economia brasileira no cenário mundial: uma reflexão sobre a situação atual à luz da história, 2012 mimeo. De 2000 a 2007, são estes os dados do IPEA: R\$ 1,268 trilhão para os portadores de títulos governamentais; 310,9 bilhões para a saúde; 149,9 bilhões para a educação (Janio de Freitas, Folha de S. Paulo, 13/11/2008). 
ao Ministério do Trabalho com uma pequena secretaria de "economia solidária” e, ainda, com programas como o Minha Casa Minha Vida - de forte incentivo econômico à cadeia produtiva da construção civil com desdobramentos relativos aos vínculos entre capital financeiro e capital investido no mercado imobiliário, destinando uma quantidade pequena, quase ínfima, de recursos para a modalidade PMCMV Entidades, que contemplaria as associações e movimentos populares (cf. C. S. Rizek, C. Santo Amore e C. Moreno de Camargo, nesse dossiê).

As políticas e programas sociais que respondem a essa conjuntura econômica e às demandas sociais se encontrariam, assim, no cruzamento entre o domínio público e privado e a gestão da vida, compondo um repertório não necessariamente coeso do horizonte neoliberal, especialmente nas injunções entre responsabilização e subjetivação individuais legitimadas pelo arcabouço meritocrático.

Essas considerações ganham relevância diante do fato de que, entre o último quartel do século XX e as primeiras décadas do século XXI, assistimos a um conjunto de transformações no âmbito do Brasil e da América Latina. Parecem ter se alterado ou mudado de forma e, em alguns casos, até mesmo desaparecido os processos de construção do tecido social a no trabalho, nos sindicatos, na proteção social, na igreja católica e nas formas associativas da vida civil - âmbito em que se constituíam as re- lações e tramas sociais assim como suas normas
Sob esse manto do "social", o que se produz é uma sociedade meritocrática que legitima um modo de dominação e oferece a justificação moral de uma distribuição desigual e insuficiente, uma sociedade que se pauta pelo avesso da igualdade, devidamente individualizada e terceirizada, que constrói uma moral da propriedade e não dos direitos, e (ou) uma moral dos direitos da propriedade como elementos que distinguem os "verdadeiros" pobres. O investimento nesses pobres poderia, então, tornar-se socialmente rentável, já que os "bons e verdadeiros" pobres não seriam transformados em dependentes ou "assistidos". A partir dessa perspectiva e desses questionamentos e inquietações, tomamos como centro de investigação algumas experiências concretas que se inserem em diferentes setores do social ou dessas "políticas sociais", como as de moradia, de transferência condicional de renda, políticas securitárias e de ativação.

Buscamos assim, por meio dessas análises de experiências, um lugar ou um espaço analítico construído de modo diverso daquele que resulta de um olhar talvez mais tradicional sobre as políticas públicas, em especial o olhar que privilegia o enfoque que as compreende como objetos ou produtos institucionais. Nosso olhar se constituiu na procura de múltiplas formas de descrição e compreensão das políticas, programas e dinâmicas sociais, dos processos que lhes são subjacentes, dos filtros de acesso, considerando os custos e os modos de sua realização prática por parte de seus "beneficiários" reais, das formas de reconhecimento sempre parciais e de suas modalidades práticas de concretização.

Recebido para publicação em 18 de outubro de 2014 Aceito em 30 de outubro de 2014

\section{REFERÊNCIAS}

BRAGA, R. A Política do precariado: do populismo à hegemonia lulista. São Paulo: Boitempo, 2012.

LAUTIER, B. Gouvernement moral des pauvres et dépolitisation des politiques publiques en Amérique latine. In: BORGEAUD-GARCIANDÍA, N.; LAUTIER, B. PENAFIEL, R.; TIZZIANI, A. (Org.). Penser le politique en 
Amérique latine: la recréation des espaces et des formes du politique. Paris: Karthala, 2009. p. 19-36.

LEITE, M. de Paula. O trabalho no Brasil dos anos 2000: duas faces de um mesmo processo. In: VÉRAS de OLIVEIRA, R.; GOMES, D.; TARGINO, I. (Orgs.). Marchas e contramarchas da informalidade do trabalho. Das origen às novas abordagens. João Pessoa: UFPB, 2011. p. 29-63.
PAULANI, L. Brasil Delivery. São Paulo: Boitempo, 2008.

SINGER, A. et al. Capitalismo e modernização periférica no Brasil do Século XXI: desigual e combinado. 2013, CENEDIC, FFLCH. Mimeo.

WACQUANT, L. Punir les pauvres. Le nouveau gouvernement de l'insécurité sociale. Marseille: Agone, 2004.

Isabel Pauline Hildegard Georges - Socióloga. Professora credenciada do PPGS e pesquisadora associada ao departamento de Sociologia da Universidade federal de São Carlos (UFSCar-DS). Pesquisadora do IRD (Institut de recherche pour le développement), França. Ocupou a cátedra francesa (cátedra Lévi-Strauss) da USP-IAU - São Carlos (2011-2012). Coordenadora da equipe brasileira do projeto ANR-10-SUDS-0008 "Latinassist" (2010-2014), e coordenadora geral do projeto, com Blandine Destremau (2013-2014). Publicações recentes: Saídas de emergência. Perder/ganhar a vida em São Paulo. São Paulo: Boitempo Editorial, 2011; Economia solidária e as novas configurações do trabalho. São Paulo: Ed. Annablume, 2012; Care e políticas públicas: o caso das "agentes comunitárias de saúde" e das "agentes de proteção social". In: HIRATA, H., GUIMARAES, N. Araújo (orgs.). Cuidado e cuidadoras: as varias faces do trabalho do care. São Paulo: Ed. Atlas, 2012, p. 166182; A produção da "demanda": viés institucional e implicações políticas da terceirização do trabalho social na periferia de São Paulo”. In: CUNHA, N. Vieira da, FELTRAN, G. de Santis. Sobre Periferias: Novos conflitos no espaço publico. Rio de Janeiro: Ed. Faperj/Lamparina, 2013, p. 159-177.

Cibele Saliba Rizek - Doutora em Sociologia. Professora do Programa de Pós Graduação em Arquitetura e Urbanismo do IAU/ Universidade de São Paulo. Pesquisadora do Centro de Estudos dos Direitos da Cidadania, também da Universidade de São Paulo. Tem experiência na área de Sociologia, com ênfase em Outras Sociologias Específicas, atuando principalmente nos seguintes temas: cidades, reestruturação produtiva, habitação, espaço público e cidadania. Publicações recentes: A coragem da crítica radical. Revista Em Pauta, v. 11, p. 215-218, 2013; Etnografias urbanas. ReDObRa, v. 12, p. 19-25, 2013; Uma Homenagem a Robert Castel. Revista Latinoamericana de Estudios del Trabajo, v. 18, p. 299-310, 2013; Políticas sociais e políticas de cultura: territórios e privatizações cruzadas. Revista Brasileira de Estudos Urbanos e Regionais, v. 15, p. 199, 2013.

Marco Ceballos - Doutor em Sociologia. Professor da Escola de Sociologia, Faculdade de Humanidades e Ciências Sociais, da Universidade Andrés Bello, UNAB, em Viña del Mar, Valparaíso. Entre 2010 e 2013 foi professor da Escola de Sociologia, Faculdade de Ciências Sociais, da Universidade Academia de Humanismo Cristiano, UAHC, em Santiago de Chile. 
